2011-02-01

\title{
Raman Scattering Analysis of Silicon Dioxide Single Crystal Treated by Direct Current Plasma Discharge
}

\author{
Dusan M. Poparic \\ Faculty of Physics, University of Belgrade, Serbia \\ Vladimir Milosavljevic \\ Technological University Dublin, vladimir.milosavljevic@tudublin.ie \\ Andrijana Zekic \\ Faculty of Physics, University of Belgrade, Serbia
}

See next page for additional authors

Follow this and additional works at: https://arrow.tudublin.ie/schfsehart

Part of the Atomic, Molecular and Optical Physics Commons, Condensed Matter Physics Commons, and the Plasma and Beam Physics Commons

\section{Recommended Citation}

D. Popovic, et al., (2011) Raman scattering analysis of silicon dioxide single crystal treated by direct current plasma discharge. Applied Physics Letters 98/5, 051503 (2011) DOI http://dx.doi.org/10.1063/ 1.3543838

This Article is brought to you for free and open access by the School of Food Science and Environmental Health at ARROW@TU Dublin. It has been accepted for inclusion in Articles by an authorized administrator of ARROW@TU Dublin. For more information, please contact arrow.admin@tudublin.ie, aisling.coyne@tudublin.ie, gerard.connolly@tudublin.ie.

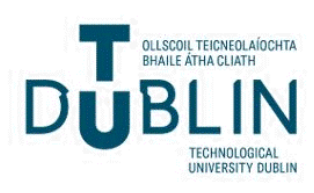


Authors

Dusan M. Poparic, Vladimir Milosavljevic, Andrijana Zekic, N Romcevic, and Steven Daniels

This article is available at ARROW@TU Dublin: https://arrow.tudublin.ie/schfsehart/180 


\title{
Raman scattering analysis of silicon dioxide single crystal treated by direct current plasma discharge
}

\author{
D. M. Popovic, ${ }^{1, a)}$ V. Milosavljevic, ${ }^{1,2, b)}$ A. Zekic, ${ }^{1}$ N. Romcevic, ${ }^{3}$ and S. Daniels ${ }^{2}$ \\ ${ }^{1}$ University of Belgrade-Faculty of Physics, Studentski trg 12, P.O. Box 44, 11001 Belgrade, Serbia \\ ${ }^{2}$ NCPST, Dublin City University, Dublin, Ireland \\ ${ }^{3}$ Institute of Physics, Pregrevica 118, P.O. Box 68, 11080 Belgrade, Serbia
}

(Received 16 August 2010; accepted 24 November 2010; published online 1 February 2011)

\begin{abstract}
Low-k materials such as silicon dioxide $\left(\mathrm{SiO}_{2}\right)$ play an important role in the semiconductor industry. Plasma has become indispensable for advanced materials processing. In this work a treatment of $\mathrm{SiO}_{2}$ single crystal by direct current plasma discharge is studied in detail. Offline metrology is conducted for silicon dioxide wafers by Raman scattering, energy-dispersive x-ray spectroscopy, and ellipsometry. Broad Raman peak at around $2800 \mathrm{~cm}^{-1}$ is observed for the treated $\mathrm{SiO}_{2}$ wafers. Effects of plasma treatment on position of this peak are reported in the paper. An analysis of this correlation could be a framework for creating virtual etch rate sensors, which might be of importance in managing plasma etching processes. (C) 2011 American Institute of Physics.
\end{abstract} [doi:10.1063/1.3543838]

The electronics industry often requires highly reliable high-performance, miniaturized devices. This necessitates the use of some high performance dielectric materials, such as silicon dioxide $\left(\mathrm{SiO}_{2}\right)$. This is one of the critical materials in the microelectronics industry and is widely used in the manufacturing of integrated circuits. Silicon dioxide and other low-k dielectric materials play an important role in the semiconductor industry in general. ${ }^{1,2}$

Plasma technologies have become dominant in microelectronics manufacturing. Plasma processing of materials is one of the most popular fields of both plasma and surface science. Plasma is widely used tool for surface modification of $\mathrm{SiO}_{2}$ layers. ${ }^{3-5}$ As the dimensions of electronic devices decrease, the role of plasma etching techniques becomes more crucial. Improving knowledge in this field is important in optimizing and controlling plasma etching processes.

A specific and important etch control requirement is end point detection with high sensitivity. In situ monitoring of the plasma etching processes plays an important role in achieving this goal. End point detection typically consists of both plasma and wafer surface metrology techniques, such as laser reflection interferometry, optical emission spectroscopy (OES), ellipsometry, etc. ${ }^{6}$

Despite the fact that it is not often used as a surface metrology technique for wafer inspection, in situ Raman spectroscopy could be useful in plasma etching analysis. ${ }^{7}$ Raman spectroscopy is highly efficient due to the fact that the Raman scattering processes involves electron-phonon interactions, which could provide highly relevant information. However, Raman analysis of plasma treated $\mathrm{SiO}_{2} / \mathrm{Si}$ system, both in situ and offline, is poorly presented in literature.

Plasma processes which there is a direct current ( $\mathrm{dc}$ ) bias on the substrate are often used in the fabrication of semiconductor devices. Despite this fact, dc plasma treatment of materials is rarely analyzed in literature. 8,9

In this paper, we describe Raman scattering measurements of single crystal silicon dioxide on silicon substrates.

\footnotetext{
${ }^{a)}$ Electronic mail: dusan@ff.bg.ac.rs.

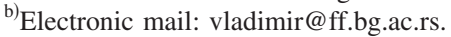

We report on a correlation between the Raman spectra and the thickness of the silicon dioxide layer. A broad peak at around $2800 \mathrm{~cm}^{-1}$ that occurs in the Raman spectra is analyzed in detail. A high level of correlation between the position of that broad peak and the $\mathrm{SiO}_{2}$ layer thickness is reported in this paper.

To perform the study, square shape wafers $(15 \mathrm{~mm}$ $\times 15 \mathrm{~mm}$ ) are placed in plasma chamber (discharge tube) as shown on Fig. 1. The angle between the plane of the wafers and a constructed channel is $45^{\circ}$. The plasma chamber is equipped with an additional gas outlet placed directly above the sample (depicting in Fig. 1 was avoided to simplify the picture). Wafers are immersed in the plasma flow during plasma treatment. The dc discharge is produced in a Pyrex tube of $5 \mathrm{~mm}$ inner diameter and an effective plasma length

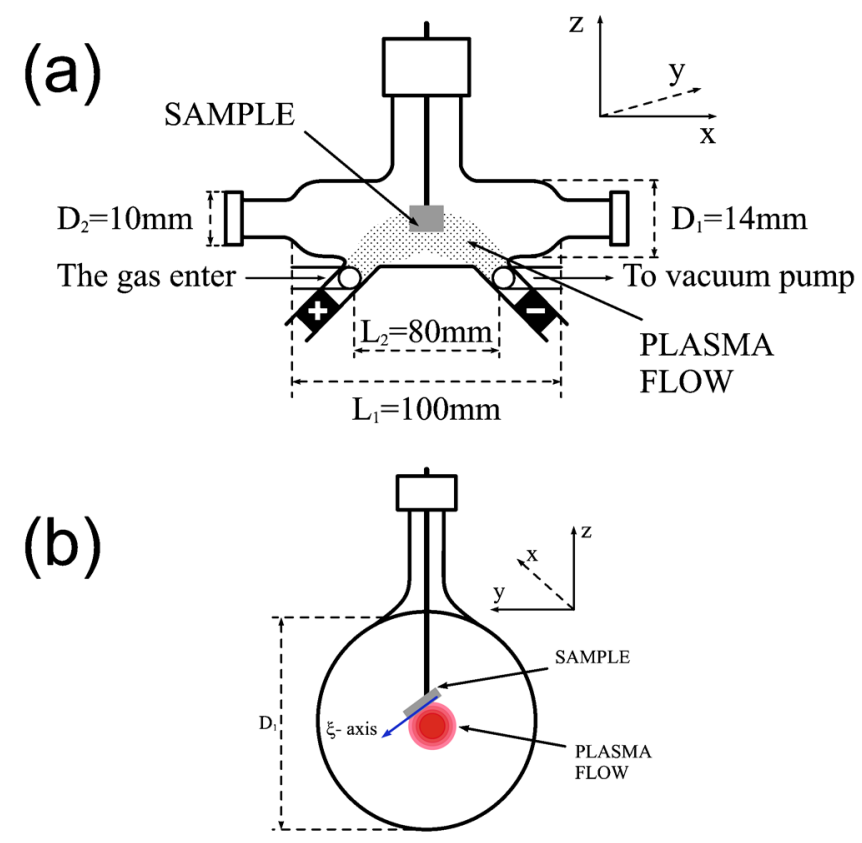

FIG. 1. (Color online) Plasma chamber with wafer shown (a) along constricted channel and (b) in the direction of constricted channel. 


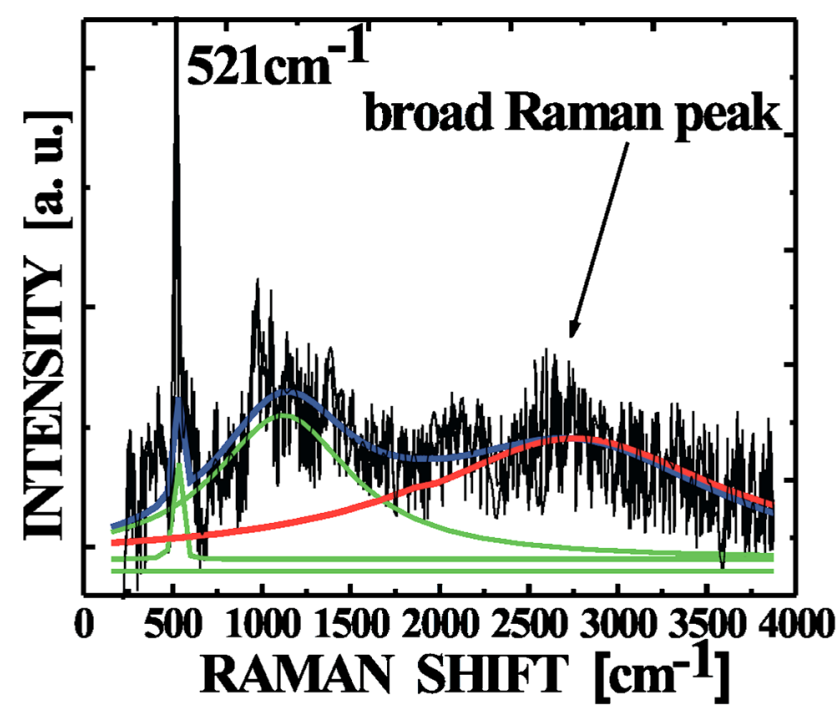

FIG. 2. (Color online) Raman spectra of untreated $\mathrm{SiO}_{2} / \mathrm{Si}$ wafer. The result of application of deconvolution by Lorentz function is shown.

of $72 \mathrm{~mm}$. The discharge tube is evacuated using a rotary vane pump that gives a background pressure of $2 \mathrm{~Pa}$. The working pressures from 50 to $266 \mathrm{~Pa}$ are achieved using a gate valve positioned above the rotary pump. Gas flow into the chamber is controlled via mass flow controllers that precisely determine the gas content in the discharge tube. The working gas is sulfur-hexafluoride (SF6) with flow rate up to $40 \mathrm{sccm}$. The power supply used was a Keithley Model 248 high voltage supply with a maximum voltage of $5 \mathrm{kV}$ and discharge current of $5 \mathrm{~mA}$. In these experiments, the maximum voltage is $2.2 \mathrm{kV}$. The wafer processing time is $30 \mathrm{~min}$.

The relative position of the wafers and the plasma flow is important, the plasma density increases in the sector near to the wafer, along the $\xi$-axis [see Fig. 1(b)], causing increased etching efficiency. Therefore, etching/deposition of/to silicon dioxide layer varies along the $\xi$-axis.

In order to inspect the chemical composition of the plasma treated wafers we used off-line energy-dispersive $\mathrm{X}$-ray spectroscopy (EDX). These experiments were carried out using a JEOL 840A instrument equipped with an INCA Penta FETx3 EDX microanalyzer. We confirmed the absence of any additional ions (such as sulfur, fluorine or other) in the structure of treated wafers; additionally there is no evidence of plasma sputtering.

The Raman spectra were excited by the $532 \mathrm{~nm}$ line of a Nd-YAG laser. We used a Chromex 2000 instrument (equipped with a charge coupled device camera, providing resolutions of $1 \mathrm{~cm}^{-1}$ to a range of $4400 \mathrm{~cm}^{-1}$ ). All Raman spectra were recorded offline at room temperature. Backscattering geometry was used during the measurement. To minimize coating of $\mathrm{SiO}_{2}$ surface by a native oxide, the samples were contained in a vacuum container.

Figure 2 shows the Raman spectra for the untreated $\mathrm{SiO}_{2} / \mathrm{Si}$ wafer (reference sample) obtained with the incident laser beam perpendicular to the $\mathrm{SiO}_{2}$ layer. Easily noticeable are a narrow peak at $521 \mathrm{~cm}^{-1}$ and its second harmonic above $1100 \mathrm{~cm}^{-1}$. The Raman peak around $521 \mathrm{~cm}^{-1}$ originates from silicon substrate. It is well described in the literature. $^{10,11}$

The broad peak at around $2800 \mathrm{~cm}^{-1}$ can be observed for untreated $\mathrm{SiO}_{2} / \mathrm{Si}$ wafer, also. In these cases, the exis- tence of such broad peak in the Raman spectra could be attributed to electronic Raman scattering. ${ }^{12}$

In general, the main process in electronic Raman scattering has single-particle and collective plasmon excitation. Keeping in mind that silicon dioxide is an insulator, we assumed that no plasmons are present. Thus, we believe that light scattering from single-particle excitations is crucial in Raman scattering for the samples investigated in this paper. It should be mentioned here that during the dielectric surface exposure to the plasma, surface and volume charging may occur in the sample. These surface charges could affect the plasma sheath conditions. Despite these facts, we assumed that the presence of surface and volume charging in $\mathrm{SiO}_{2} / \mathrm{Si}$ samples could be neglected. The main reason for such an assumption is in the fact that a dc plasma was used in our experiments. The appearance of charge imbalance in a single crystal is followed by a relaxation processes. In the case of dielectrics, this process occurs on a much longer time scale due to the low conductivity. If some time-varying plasma signal is applied (for instance, pulsed dc) charge redistribution cannot be fully carried out, so surface and volume charge play an important role in the process. This is not the case if a dc plasma is applied.

Raman scattering spectra are often analyzed with the help of a Lorentzian function or by the convolution of a Lorentzian and Gaussian curve. ${ }^{13,14}$ In this work, we analyze the Raman spectrum fitted with Lorentzians. The same fitting procedure is applied for both untreated and plasma treated $\mathrm{SiO}_{2} / \mathrm{Si}$ wafers. Line shapes obtained in this way are shown in Fig. 2. The bottom green line from Fig. 2 belongs to the Rayleigh scattering peak.

Agreement between experimental results and the convolution curve obtained in this way is very good.

Raman measurements were carried out for various positions (spaced by $2 \mathrm{~mm}$ ) of the plasma treated $\mathrm{SiO}_{2} / \mathrm{Si}$ wafer surface. All points lie on the straight line $[\xi$-axis from Fig. $1(\mathrm{~b})]$.

First, it should be emphasized that no additional Raman peak appears as a result of plasma treatment. Further, the broad Raman peak shifts to the low-energy side of spectra as position on the $\xi$-axis changes. As we mentioned before, the etching efficiency of silicon dioxide wafer is increased from point to point along the $\xi$-axis [see Fig. 1(b)]. Due to the increase of etch efficiency along $\xi$-axis, the thickness of the $\mathrm{SiO}_{2}$ layer decreases. The thickness of the silicon dioxide layer has been determined by off line ellipsometry technique.

We confirm that the thickness of $\mathrm{SiO}_{2}$ layer does not change with movement along any direction perpendicular to the $\xi$-axis. This is because of the fact that the plasma density is only slightly changed in the plane perpendicular to the $\xi$-axis; therefore, etching efficiency for points that lie along the same direction perpendicular to the $\xi$-axis should be the same.

A summary of the broad Raman peak position and $\mathrm{SiO}_{2}$ layer thickness measured for various points along $\xi$-axis is presented in Fig. 3. Remarkably, the position of this peak shift to the lower energy as the thickness of $\mathrm{SiO}_{2}$ layer decreases. This correlation is obvious for the whole range of $\xi$-axis, i.e., from higher to lower points along surface of treated wafer.

The Raman lines for the phonon mode shift to the lower energies and broaden with increased temperature; this shift is about $10 \mathrm{~cm}^{-1}$ for temperature range about $300-700 \mathrm{~K}{ }^{15} \mathrm{It}$ 




FIG. 3. Position of broad Raman peak and $\mathrm{SiO}_{2}$ layer thickness vs. position along $\xi$-axis. Lines should guide the eyes.

is easy to assume that the position of the broad Raman peak described in this paper is T-dependent, also. Thus given that the shift of the broad peak described in this paper is about $700 \mathrm{~cm}^{-1}$, one could conclude that the T-shift of the same peak could not play a crucial role. In other words, the T-shift of the broad Raman peak could not affect significantly an in situ diagnostic application.

To conclude, we investigated treatment of $\mathrm{SiO}_{2} / \mathrm{Si}$ wafers by dc plasma discharge. The main surface analysis used was Raman spectroscopy. We focused on the Raman broad peak around $2800 \mathrm{~cm}^{-1}$. This broad peak shifts to the lowenergy side of Raman spectra with decreasing silicon dioxide layer thickness. The position of this peak is highly correlated with layer thickness and other parameters of this peak (as integrated intensity, etc.) are irrelevant in this case. This fact is important for any possible application of broad peak analysis. Namely, it is well known that numerous problems could appear in the in situ inspection of plasma etching process by using some incident light beam. One of the major problems is interaction of the plasma with the incident light beam, such as scattering and absorption. Using only the position of broad Raman peak as an etch rate virtual sensor, most of these problems could be avoided. Furthermore, the presence of the laser beam should not affect the condition of wafer surface as well as the main plasma parameters. In other words, the plasma etching process should not be perturbed significantly by the in situ Raman measurement. These measurements could be conducted for more than one spot on the wafer, simultaneously or in a short time window. In light of these facts, we can conclude that a broad Raman peak is a good representation of plasma surface interactions, i.e., of main plasma processing parameters.

This work was a part of the project supported by Ministry of Science and Technological Development of the Republic of Serbia (project No. 171006). V.M. is grateful to the fellowship award funded by SFI Precision project, Ireland. The authors wish to thank M. Radovic for assistance with ellipsometric measurements.

${ }^{1}$ K. Postava, T. Yamaguchi, and M. Horie, Appl. Phys. Lett. 79, 2231 (2001).

${ }^{2}$ I. A. Mowat, X. F. Lin, T. Fister, M. Kendall, G. Chao, and M. H. Yang, Appl. Surf. Sci. 252, 7182 (2006).

${ }^{3}$ M. N. A. Dewan, P. J. McNally, T. Perova, and P. A. F. Herbert, Microelectron. Eng. 65, 25 (2003).

${ }^{4}$ A. Paskaleva and E. Atanassova, Solid-State Electron. 42, 777 (1998).

${ }^{5}$ H. Yamada, K. Kuwahara, and H. Fujiyama, Thin Solid Films 316, 6 (1998).

${ }^{6}$ K. L. Seaward and N. J. Moll, J. Vac. Sci. Technol. B 10, 46 (1992).

${ }^{7}$ M. Mermoux, L. Fayette, B. Marcus, N. Rosman, L. Abello, G. Lucazeau, Diamond Relat. Mater. 4, 745 (1995).

${ }^{8}$ K. N. Pandiyaraj, V. Selvarajan, M. Pavese, P. Falaras, and D. Tsoukleris, Curr. Appl. Phys. 9, 1032 (2009).

${ }^{9}$ R. Lothian, F. Ren, and S. J. Pearton, Semicond. Sci. Technol. 7, 1199 (1992).

${ }^{10}$ P. A. Temple and C. E. Hathaway, Phys. Rev. B 7, 3685 (1973).

${ }^{11}$ M. M. Khayyat, G. K. Banini, D. G. Hasko, and M. M. Chaudhri, J. Phys. D 36, 1300 (2003).

${ }^{12}$ M. V. Klein, in Light Scattering in Solids, edited by M. Cardona (Springer, Berlin, 1983), Vol. I.

${ }^{13}$ J. Tang and A. C. Albrecht, in Raman Spectroscopy, edited by H. Szmanski (Plenum, New York, 1970).

${ }^{14}$ B. H. Henry, in Raman Spectroscopy: Sixty Years On, edited by R. During (Elsevier, Amsterdam, 1990), Vol. 10.

${ }^{15}$ S. Ichikawa, J. Suda, T. Sato, and Y. Suzuki, J. Raman Spectrosc. 34, 135 (2003). 